\title{
Development and validation of a nomogram for prediction of the risk of positive hidden blood loss in the perioperative period of single-level thoracolumbar burst fracture
}

\author{
Haosheng Wang ${ }^{1 \dagger}$, Tingting Fan ${ }^{2 \dagger}$, Zhi-Ri Tang ${ }^{3}$, Wenle Li, ${ }^{4,5}$ Linjing Liu ${ }^{3}$ and Qiang Lin ${ }^{1 *}$
}

\begin{abstract}
Background: This study aimed to develop and validate an individualized nomogram to predict the risk of positive hidden blood loss (HBL) in patients with single-level thoracolumbar burst fracture (TBF) during the perioperative period.

Methods: We conducted a retrospective investigation including 150 consecutive patients with TBL, and the corresponding patient data was extracted from March 2013 to March 2019. The independent risk factors for positive HBL were screened using univariate and multivariate logistic regression analyses. According to published literature and clinical experience, a series of variables were selected to develop a nomogram prediction model for positive HBL. The area under the receiver operating characteristic curves (AUC), C-index, calibration plot, and decision curve analysis (DCA) were used to evaluate the performance of the prediction model. Bootstrapping validation was performed to evaluate the performance of the model.

Results: Among the 150 consecutive patients, 62 patients were positive for HBL (38.0\%). The multivariate logistic regression analysis showed that the six risk factors of age, length of surgical incision, duration of operation, percentage of vertebral height restoration $\left(P_{1} \%\right)$, preoperative total cholesterol, and preoperative fibrinogen were independent risk factors of positive HBL. The C-index was 0.831 (95\% Cl 0.740-0.889) and 0.845 in bootstrapping validation, respectively. The calibration curve showed that the predicted probability of the model was consistent with the actual probability. Decision curve analysis (DCA) showed that the nomogram had clinical utility.

Conclusion: Overall, we explored the relationship between the positive HBL requirement and predictors. The individualized prediction model for patients with single-level TBF can accurately assess the risk of positive HBL and facilitate clinical decision making. However, external validation will be needed in the future.
\end{abstract}

Keywords: Hidden blood loss, Blood loss, Thoracolumbar burst fracture, Risk factors, Nomogram

\footnotetext{
* Correspondence: lqcf202103@sina.com

${ }^{+}$Haosheng Wang and Tingting Fan contributed to the work equally and

should be regarded as co-first authors.

'Department of Orthopedics, Baoji City Hospital of Traditional Chinese

Medicine, 43 Baofu Road, Baoji 721000, Shaanxi Province, People's Republic of China

Full list of author information is available at the end of the article
}

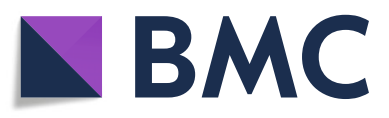

(๑) The Author(s). 2021 Open Access This article is licensed under a Creative Commons Attribution 4.0 International License, which permits use, sharing, adaptation, distribution and reproduction in any medium or format, as long as you give appropriate credit to the original author(s) and the source, provide a link to the Creative Commons licence, and indicate if changes were made. The images or other third party material in this article are included in the article's Creative Commons licence, unless indicated otherwise in a credit line to the material. If material is not included in the article's Creative Commons licence and your intended use is not permitted by statutory regulation or exceeds the permitted use, you will need to obtain permission directly from the copyright holder. To view a copy of this licence, visit http://creativecommons.org/licenses/by/4.0/. The Creative Commons Public Domain Dedication waiver (http://creativecommons.org/publicdomain/zero/1.0/) applies to the data made available in this article, unless otherwise stated in a credit line to the data. 


\section{Introduction}

Thoracolumbar fractures are commonly encountered in clinical practice, and fractures of the burst type account for 25 to $58 \%$ [1-3] of all thoracolumbar spinal fractures. Thoracolumbar burst fractures (TBF) shorten people's lives and cause impairment in the quality of life [2-4]. Surgical intervention is often needed to alleviate pain, rebuild spinal stability, restore function, and relieve spinal cord compression. Meanwhile, surgical intervention can also facilitate nursing care and reduce prolonged bed rest complications $[5,6]$.

Remarkably, intraoperative blood loss is a prevalent issue that can be encountered in the surgical treatment of thoracolumbar burst fractures [7, 8]. Nevertheless, patients with thoracolumbar burst fractures occasionally require a transfusion despite what appears to be a limited intraoperative blood loss. This may be due to undetectable blood loss, called hidden blood loss (HBL). The concept of HBL was first described in 2000 by Sehat et al. [9] who found that HBL accounted for $26 \%$ and $49 \%$ of total blood loss after total knee and hip replacement, respectively. Subsequently, many studies about HBL after orthopedic surgery have been widely concerned by many scholars. There have been several reports on HBL in spine surgery, including anterior cervical fusion, percutaneous kyphoplasty, posterior lumbar decompression and fusion (PLDF), single-level open or minimally invasive transforaminal interbody fusion (MIS-TLIF) [10-13]. Nevertheless, few reports associated with HBL in thoracolumbar burst fractures are available.

The HBL during the perioperative period is usually ignored, but it is important for the prognosis and outcome. Despite satisfactory management of blood loss during the perioperative period, it is puzzling that patient with thoracolumbar burst fractures often have lower postoperative HB levels than expected. We therefore deduced that it might be due to HBL. Unfortunately, however, few studies have been conducted to investigate the $\mathrm{HBL}$ in patients with thoracolumbar burst fractures during the perioperative period. In this study, we aimed to explore the risk factors related to HBL in patients with single-level TBF and develop an accurate individualized risk of HBL predictive tool based on routine parameters.

\section{Materials and methods}

The study protocol was approved by the Baoji City Hospital of Traditional Chinese Medicine (Baoji, China) and the Research Ethics review board (NO. 2021GYKJD5N). Due to the retrospective nature of the study, a waiver of informed consent was obtained. From March 2013 to March 2019, patients with symptomatic single-level TBF were obtained and analyzed. The inclusion criteria for the study were as follows: (1) age of $\geq 18$; (2) burst fracture (AO classification); (3) fracture level: T11-L2; (4) Thoracolumbar Injury Classification and Severity Score (TLICS) $\geq 5$ [14, 15]; and (5) surgical approach: posterior instrumentation. The exclusion criteria were as follows: (1) organ with dysfunction such as liver or kidney, abnormal bleeding, or abnormal coagulation function; (2) history of surgery for spinal disorder; (3) cerebrospinal fluid leakage (CSF fistula) or spontaneous; (4) intraoperative and postoperative use of hemostatic drugs; and (5) patients with incomplete medical records. HBL $\geq 470 \mathrm{ml}$ was defined as an HBL-positive group, according to the definition of $\mathrm{HBL}$, calculated by gross equation, and $\mathrm{HBL}<470 \mathrm{ml}$ was an HBL negative group [16].

\section{Data collections}

We retrospectively collected the patients' data, including age, sex, body mass index (BMI), underlying diseases (hypertension, diabetes, chronic obstructive pulmonary disease (COPD)), history of smoking, history of alcohol, history of blood transfusion, and chronic steroid use. The preoperative visual analogue score (VAS), Japanese Orthopaedic Association (JOA) scores, and 36-Item Short Form Health Survey (SF-36) were recorded.

Surgery-related parameters including duration from admission to surgery, length of surgical incision, levels of fusion, and duration of operation were obtained from an electronic medical record system. The parameters relevant to the perioperative fluid management strategy, including intraoperative infusion of crystalloids, intraoperative infusion of colloids, autologous blood transfusion, and allogeneic blood transfusion, were recorded. Meanwhile, routine preoperative laboratory test data, including hematologic tests, blood chemistry, coagulation tests, and liver function tests, was obtained from the clinical laboratory database of the Baoji City Hospital of Traditional Chinese Medicine. In addition, to assess the influence of fractured vertebral height on hidden blood loss, we calculated percentages of vertebral height restoration $\left(\mathrm{P}_{1} \%\right)$ and vertebral height loss $\left(\mathrm{P}_{2} \%\right)$ by measuring preoperative and postoperative $\mathrm{X}$-ray parameters [7]. The formulae for $\mathrm{P}_{1} \%$ and $\mathrm{P}_{2} \%$ calculation are as follows:

$$
\begin{aligned}
& \mathrm{P} 1 \%=\frac{e-a}{d} \times 100 \% \\
& \mathrm{P} 2 \%=\frac{d-a}{d} \times 100 \% \\
& d=\frac{b+c}{2}
\end{aligned}
$$

Here, $a$ is the height of the fractured vertebra, $b$ is the upper anterior vertebral height adjacent to the fractured vertebra, $c$ is the lower anterior vertebral height adjacent 
to the fractured vertebra, $d$ is the predicted height of each fractured vertebra which is calculated according to the average height of the two adjacent vertebrae ( $b$ and $c)$, and $e$ is the postoperative vertebral body height. This parameter measurement method is shown in Fig. 1.

\section{Management and calculation of HBL}

According to the formula by Nader et al. [17], patient's blood volume (PBV) was calculated as follows:

$$
\mathrm{PBV}=\mathrm{k} 1 \times \text { height }(\mathrm{m})+\mathrm{k} 2 \times \text { weight }(\mathrm{kg})+\mathrm{k} 3
$$

Here, for male, $\mathrm{k} 1=0.3669, \mathrm{k} 2=0.03219$, and $\mathrm{k} 3=$ 0.6041 ; for female, $\mathrm{k} 1=0.3561, \mathrm{k} 2=0.03308$, and $\mathrm{k} 3=$ 0.1833 .

According to the gross formula, total blood loss (TBL) was calculated as follows:

$$
\mathrm{TBL}=\mathrm{PBV} \times\left(\mathrm{Hct}_{\text {pre }}-\mathrm{Hct}_{\text {post }}\right) / \mathrm{Hct}_{\text {ave }}
$$

where Hct $_{\text {pre }}$ was defined as the Hct on preoperative day 1 Hct $_{\text {post }}$ was defined as the Hct on postoperative day 3 , and $\mathrm{Hct}_{\text {ave }}$ was defined was the average of Hct $\mathrm{Hre}_{\mathrm{p}}$ and $\mathrm{Hct}_{\text {post }}$. Subsequently, intraoperative blood loss was determined as follows:
Intraoperative blood loss = estimating the volume of blood in the + weighing blood-soaked gauze

Visible blood loss $(\mathrm{VBL})=$ intraoperative blood loss + postoperative drainage

Therefore, HBL was defined as follows:

$$
\mathrm{HBL}=\mathrm{TBL}-\mathrm{VBL}
$$

when there was perioperative blood transfusion, HBL could be defined as follows:

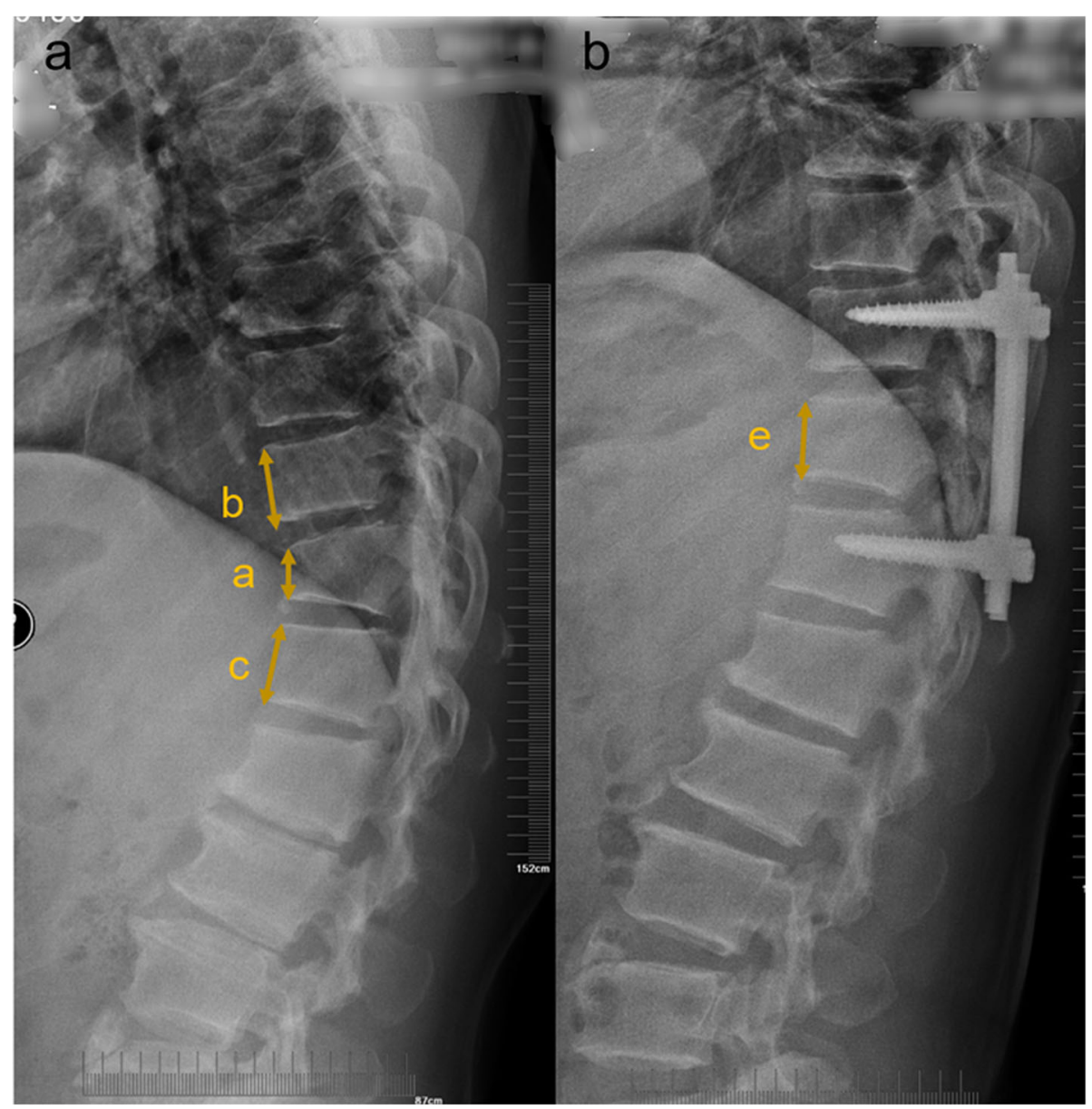

Fig. 1 Radiographic measurement of fractured vertebral body. a Preoperative lateral radiograph; $a$ is the height of the fractured vertebra; $b$ is the upper anterior vertebral height adjacent to the fractured vertebra, and $c$ is the lower anterior vertebral height adjacent to the fractured vertebra. b Postoperative lateral radiograph; $e$ is the postoperative vertebral body height. Note: $d$ is the predicted height of each fractured vertebra which is calculated according to the average height of the two adjacent vertebrae ( $b$ and $c$ ) 
$\mathrm{HBL}=\mathrm{TBL}-\mathrm{VBL}+$ autologous blood transfusion + allogeneic blood transfusion

\section{Statistical analysis}

Continuous data is presented as the means \pm standard deviations. Categorical variables were grouped and compared using the $\chi^{2}$ test or Fisher's exact test. Continuous variables were compared using Student's $t$-test. Risk factor analysis was performed using univariate and multivariate logistic regression analyses. In order to facilitate the establishment of the prediction model, cut-off values for continuous variables were determined by the receiver operating characteristic (ROC) curve (Figure S1). Variables showing statistical significance in the univariate analysis were included in the multivariate logistic regression analysis, and the forward stepwise method was used to select the variables that were eventually included in the model. According to the results of the regression coefficients of independent variables, an individual nomogram prediction model for HBL was established. The performance of the model was assessed in terms of discrimination and calibration. The discrimination of our prediction model is usually evaluated by calculating the area under the curve (AUC) of the ROC curve. Typically, the AUC values of the models were between 0 and 1 . A prediction model with an AUC in the range of 0.5-0.75 was considered acceptable, and AUC $>0.75$ indicated that the models possessed excellent discriminative power. The calibration of the nomogram was evaluated with a calibration curve. The Hosmer-Lemeshow test was conducted to assess the goodness-of-fit of the nomogram. A relatively corrected C-index (1000 bootstrap resamples) of the nomogram was also determined in this dataset. Furthermore, the decision curve analysis (DCA) was performed to evaluate the net benefit of the nomogram to the decision. All the analyses were performed by using IBM SPSS 23.0 (SPSS Inc) and R software version 4.0.2 (http://www.r-project.org) with the "rms," "SimDesign," and "AICcmodavg" packages [1820].

\section{Results}

In this study, a total of 178 consecutive cases were collected. According to the inclusion and exclusion criteria, 5 intraoperative dural ruptures, 10 postoperative tranexamic acid use, 2 intraoperative thrombin drug use, and 11 missing laboratory parameters about Hct $_{\text {post }}, 28$ patients were excluded. Finally, 150 cases were included, 99 (66.0\%) males and 51 (34.0\%) females, mean (38.1 \pm 10.3 ) years old. The TBL was $1134.5 \pm 128.3 \mathrm{ml}$, the VBL was $269.1 \pm 82.5 \mathrm{ml}$, and the HBL was $491.3 \pm 104.5 \mathrm{ml}$ (50.3\% of TBL). Among the 150 cases, 93 cases were negative $\mathrm{HBL}$, i.e., $\mathrm{HBL}(-)$ group; 57 cases were positive HBL, i.e., HBL (+) group.
Among the HBL (-) and HBL (+) group, there were statistically significant differences in age $(p<0.001)$, hypertension $(p<0.001)$, history of smoking $(p<0.001)$, diabetes $(p=0.017)$, duration from admission to surgery $(p=0.021)$, length of surgical incision $(p<0.001)$, duration of operation $(p<0.001), \mathrm{P}_{1} \%(p<0.001), \mathrm{P}_{2} \%(p<$ $0.001)$, preoperative total cholesterol $(p<0.001)$, preoperative triglyceride $(p<0.001)$, preoperative $\mathrm{Hb}(p=$ $0.017)$, preoperative PT $(p<0.001)$, preoperative Fib $(p$ $=0.038)$, and preoperative APTT $(p<0.001)$. There were no significant differences in remaining parameters between the HBL (-) and HBL (+) group. The detailed results of the parameters are shown in Table 1.

The univariate logistics analysis showed that statistically significant risk factors were age, hypertension, diabetes, history of smoking, COPD, duration from admission to surgery, length of surgical incision, duration of operation, $\mathrm{P}_{1} \%$, intraoperative infusion of crystalloids, preoperative total cholesterol, preoperative triglyceride, preoperative ALB, preoperative PT, and preoperative fibrinogen $(P<0.05)$. Statistically significant variables selected from the univariate logistics analysis were imported into the non-conditional binary multivariate logistic regression. The six factors of age, duration from admission to surgery, duration of operation, $\mathrm{P}_{1} \%$, preoperative total cholesterol, and preoperative fibrinogen were independent risk factors of positive HBL (Table 2) $(P<0.05)$. Next, we developed a nomogram based on the result of logistic regression analysis (Fig. 2).

The area under the curve (AUC) of the receiver operating characteristic (ROC) curve (Fig. 3) of the nomogram was 0.831 ( $95 \% \mathrm{CI}, 0.740$ to 0.889 ), which indicated that our prediction model showed satisfied discrimination. The calibration curve of the nomogram showed good agreement between the observation cases and prediction cases in this dataset (Fig. 4). Subsequently, the C-index of this model was 0.843 ( $95 \%$ CI 0.749 to 0.905 ) in this dataset and was identified to be 0.845 via bootstrapping validation (Bootstrap $=1000$ ).

To evaluate the clinical usefulness of the predictive model, a decision analysis (DCA) was performed on the data. The DCA is a novel method that assesses the clinical net benefit of the nomogram. The DCA is demonstrated in Fig. 5. For clinicians and patients, if the threshold was set at 8.1-95.2\% and above, the use of this model to predict the probability of patient transfusion is more beneficial than this scheme.

\section{Discussion}

HBL refers to blood loss that cannot be measured directly in vivo after some of the larger trauma and surgery that is experienced, and this part excludes blood loss 
Table 1 Comparison of variables between the positive HBL group and negative HBL group

\begin{tabular}{|c|c|c|c|c|}
\hline & Total & Negative HBL group & Positive HBL group & $P$ value \\
\hline Number of patients & 150 & 93 & 57 & \\
\hline Age (year) & $38.1(10.3)$ & $34.3(9.5)$ & $49.2(8.1)$ & $<0.001$ \\
\hline \multicolumn{5}{|l|}{$\operatorname{Sex}(\%)$} \\
\hline Female & $99(66.0)$ & $60(64.5)$ & 39 (68.4) & 0.711 \\
\hline Male & $51(34.0)$ & $33(35.5)$ & 18 (31.6) & \\
\hline \multicolumn{5}{|l|}{ BMI (\%) } \\
\hline$<25$ & $77(51.3)$ & $53(57.0)$ & $24(42.1)$ & 0.065 \\
\hline$\geqq 25$ & $73(48.7)$ & $40(43.0)$ & $33(57.9)$ & \\
\hline \multicolumn{5}{|l|}{ Hypertension (\%) } \\
\hline No & $56(37.3)$ & $45(48.4)$ & $11(19.3)$ & $<0.001$ \\
\hline Yes & $94(62.7)$ & $50(51.6)$ & $46(80.7)$ & \\
\hline \multicolumn{5}{|l|}{ Diabetes (\%) } \\
\hline No & $63(42.0)$ & $53(57.0)$ & $10(17.5)$ & 0.017 \\
\hline Yes & $87(58.0)$ & $40(43.0)$ & $47(82.5)$ & \\
\hline \multicolumn{5}{|l|}{ History of smoking (\%) } \\
\hline No & 77 (51.3) & $61(65.6)$ & $16(28.1)$ & $<0.001$ \\
\hline Yes & $73(48.7)$ & $32(34.4)$ & $41(71.9)$ & \\
\hline \multicolumn{5}{|l|}{ History of alcohol (\%) } \\
\hline No & $68(42.5)$ & $40(38.8)$ & $28(49.1)$ & 0.165 \\
\hline Yes & $92(57.5)$ & $63(61.2)$ & $29(50.9)$ & \\
\hline \multicolumn{5}{|l|}{ Chronic steroid use (\%) } \\
\hline No & $133(88.7)$ & $80(86.0)$ & $53(93.0)$ & 0.321 \\
\hline Yes & $17(11.3)$ & $13(14.0)$ & $4(7.00)$ & \\
\hline \multicolumn{5}{|l|}{ COPD (\%) } \\
\hline No & $145(96.7)$ & $90(96.8)$ & $55(96.5)$ & 0.965 \\
\hline Yes & $5(3.30)$ & $3(3.20)$ & $2(3.50)$ & \\
\hline \multicolumn{5}{|l|}{ History of blood transfusion (\%) } \\
\hline No & $149(99.3)$ & $92(98.9)$ & $57(100.0)$ & 0.421 \\
\hline Yes & $1(0.7)$ & $1(1.10)$ & $0(0.00)$ & \\
\hline Preoperative VAS & $5.9[4.9,7.1]$ & $6.8[4.8,7.0]$ & $5.8[4.9,7.0]$ & 0.265 \\
\hline Preoperative JOA & $12.7[10.0,16.5]$ & $13.1[10.0,16.0]$ & $13.2[10.8,15.5]$ & 0.228 \\
\hline Preoperative SF-36 & $70.6(5.4)$ & $71.3(6.0)$ & $69.9(6.8)$ & 0.65 \\
\hline Duration from admission to surgery (day) & $0.6(0.5)$ & $0.48(0.5)$ & $0.72(0.3)$ & 0.021 \\
\hline Length of surgical incision (cm) & $14.0(1.6)$ & $12.9(1.1)$ & $15.8(0.9)$ & $<0.001$ \\
\hline Duration of operation (min) & $164.6(18.4)$ & $157.0(13.8)$ & $178.2(15.5)$ & $<0.001$ \\
\hline$P_{1} \%$ & $38.3[36.7,44.1]$ & $37.2[36.0,36.4]$ & $46.0[41.4,48.1]$ & $<0.001$ \\
\hline$P_{2} \%$ & $29.7[27.0,31.8]$ & $30.9[26.9,34.7]$ & $28.5[26.9,30.9]$ & 0.011 \\
\hline \multicolumn{5}{|l|}{ Level } \\
\hline $\mathrm{T} 11$ & $64(43.0)$ & $43(46.1)$ & $22(37.9)$ & 0.637 \\
\hline $\mathrm{T} 12$ & $63(41.9)$ & $38(40.8)$ & 25 (43.6) & \\
\hline L1 & $23(15.2)$ & $12(13.1)$ & $11(18.5)$ & \\
\hline \multicolumn{5}{|c|}{ Levels of fusion (\%) } \\
\hline T9-L1 & $73(48.7)$ & $50(53.8)$ & $23(40.4)$ & 0.4408 \\
\hline T10-L2 & $61(40.7)$ & $36(38.7)$ & $25(43.9)$ & \\
\hline
\end{tabular}


Table 1 Comparison of variables between the positive HBL group and negative HBL group (Continued)

\begin{tabular}{|c|c|c|c|c|}
\hline & Total & Negative HBL group & Positive HBL group & $P$ value \\
\hline T11-L3 & $16(10.7)$ & $7(7.50)$ & $9(15.8)$ & \\
\hline Intraoperative infusion of crystalloids (ml) & $1569.0[1317.0,1862.3]$ & $1561.1[1359.5,1856.2]$ & $1538.1[1239.2,1889.9]$ & 0.706 \\
\hline Intraoperative infusion of colloids (ml) & $812.4[627.0,995.5]$ & $809.6[618.0,1011.3]$ & $815.1[670.2,939.5]$ & 0.876 \\
\hline \multicolumn{5}{|l|}{ Autologous blood transfusion (\%) } \\
\hline No & $120(80.0)$ & $77(82.8)$ & $43(75.4)$ & \multirow[t]{2}{*}{0.470} \\
\hline Yes & $30(20.0)$ & $16(17.2)$ & $14(24.6)$ & \\
\hline \multicolumn{5}{|l|}{ Allogeneic blood transfusion (\%) } \\
\hline No & $115(76.7)$ & $75(80.6)$ & $40(70.2)$ & \multirow[t]{2}{*}{0.775} \\
\hline Yes & $35(23.3)$ & $18(19.4)$ & $17(29.8)$ & \\
\hline Preoperative total cholesterol (mmol/L) & $4.7[3.3,6.4]$ & $3.7[3.2,5.0]$ & $6.8[5.2,7.0]$ & $<0.001$ \\
\hline Preoperative triglyceride (mmol/L) & $2.1[1.4,3.5]$ & $1.7[1.0,2.3]$ & $3.8[3.2,4.9]$ & $<0.001$ \\
\hline Preoperative Hct (\%) & $40.9(3.5)$ & $40.3(3.9)$ & $42.6(4.4)$ & 0.405 \\
\hline Preoperative Hb (g/L) & $122.8(13.4)$ & $124.2(15.2)$ & $119.8(10.2)$ & 0.017 \\
\hline Preoperative ALB (g/L) & $39.7(4.8)$ & $39.2(4.0)$ & $40.6(4.3)$ & 0.040 \\
\hline Preoperative PT (s) & $10.2(0.6)$ & $10.1(0.4)$ & $10.9(0.5)$ & $<0.001$ \\
\hline Preoperative APTT (s) & $33.4(2.7)$ & $35.7(2.8)$ & $32.9(2.8)$ & $<0.001$ \\
\hline Preoperative Fib (mg/dL) & $4.7(0.9)$ & $4.9(1.0)$ & $4.6(0.7)$ & 0.038 \\
\hline
\end{tabular}

Abbreviations: BMI body mass index, COPD chronic obstructive pulmonary disease, JOA Japanese Orthopaedic Association, VAS visual analogue score, SF-36 36-Item Short Form Health Survey, $P_{1} \%$ percentages of vertebral height restoration, $P_{2} \%$ percentages of vertebral height loss, $H c t$ hematocrit, $H b$ hemoglobin, $A L B$ albumin, PT prothrombin time, APTT activated partial thromboplastin time

that can be quantified directly and postoperative drainage [21]. At present, the mechanism of HBL remains unclear, and some scholars believe that HBL is related to trauma, incomplete intraoperative hemostasis, and postoperative anticoagulant therapy. Another part of scholars believe that it is caused by the accidental opening of the capillary bed due to intraoperative hemolysis, the entrance of a large amount of blood into the body cavity in the perioperative period, and the entrance of marrow fat into the blood circulation. Since Sehat et al. [21] reported that HBL in patients undergoing total hip arthroplasty was $49 \%$ of the TBL, spine surgeons are becoming increasingly aware that HBL plays an important role in spine surgery. An increasing number of studies have attempted to investigate the perioperative HBL and its related risk factors in spine surgery. In a prospective study, Smorgick et al. [22] reported that patients undergoing posterior lumbar internal fixation (PLIF) had 600 $\mathrm{ml}$ of HBL, which accounts for $42 \%$ of the TBL [23]. In another retrospective study, Wen et al. [8] reported that HBL in thoracolumbar burst fracture patients during the perioperative period was $303.5 \mathrm{ml}$, accounting for $67.5 \%$ of TBL. In literature, it is very rarely reported. In this study, we identified independent risk factors associated with positive HBL as follows: age, duration from admission to surgery, duration of operation, $\mathrm{P}_{1} \%$, preoperative total cholesterol, and preoperative fibrinogen.
Based on our research data and literature reports, we presume that the reasons may be as follows. Bone marrow hematopoiesis and the ability to store red blood cells in the body decline with increasing age and poor compensatory ability for blood loss anemia, resulting in a prolonged postoperative hematocrit in a low state, ultimately leading to high hidden blood loss calculated by gross formula $[24,25]$. In a subset of patients with COPD as well as a long history of smoking, there is an increased amount of superoxide anion in the body, decreased capillary elasticity, and increased fragility. Meanwhile, because thoracolumbar burst fractures are highenergy injuries, the stress and inflammatory response induced by trauma and anesthesia can lead to increased peripheral capillary permeability and damage to the vascular endothelium $[24,26]$. These insults result in diminished regulatory capacity of the peripheral capillary bed, allowing increased blood loss and impaired blood return.

Surgical trauma may cause a stress response, which stimulates the synthesis of unsaturated fatty acids such as cholesterol and triacylglycerol in the blood. In our work, we observed that the concentrations of cholesterol and triacylglycerol were higher in the HBL $(+)$ group compared with the HBL (-) group. Consequently, cholesterol was indicated as a risk factor for HBL $(+)$ in multivariate logistics regression analysis. However, to 
Table 2 Univariate and multivariate logistic regression model analyses of positive HBL in this study

\begin{tabular}{|c|c|c|c|c|}
\hline & Univariate analysis & & Multivariate analysis & \\
\hline & OR $(95 \% \mathrm{Cl})$ & $P$ value & OR $(95 \% \mathrm{Cl})$ & $P$ value \\
\hline Age (year) & $4.055(2.417-6.805)$ & $<0.001$ & $3.056(1.956-4.965)$ & 0.012 \\
\hline $\operatorname{Sex}(\%)$ & $1.099(0.663-1.822)$ & 0.715 & NA & \\
\hline BMI (\%) & $1.668(1.021-2.726)$ & 0.041 & NA & \\
\hline Hypertension (\%) & $2.242(1.351-3.721)$ & 0.002 & NA & \\
\hline Diabetes (\%) & $2.584(1.548-4.316)$ & $<0.001$ & NA & \\
\hline History of smoking (\%) & $2.735(1.651-4.531)$ & $<0.001$ & NA & \\
\hline History of alcohol (\%) & $0.848(0.520-1.383)$ & 0.509 & NA & \\
\hline Chronic steroid use (\%) & $1.391(0.800-2.419)$ & 0.242 & NA & \\
\hline COPD (\%) & $2.589(1.273-5.265)$ & 0.009 & NA & \\
\hline History of blood transfusion (\%) & $1.169(0.611-2.237)$ & 0.637 & NA & \\
\hline Preoperative VAS & $1.444(0.832-2.506)$ & 0.192 & NA & \\
\hline Preoperative JOA score & $1.096(0.635-1.893)$ & 0.741 & NA & \\
\hline Preoperative SF 36 & $0.665(0.395-1.119)$ & 0.125 & NA & \\
\hline Duration from admission to surgery (day) & $2.344(1.418-3.874)$ & $<0.001$ & $1.985(1.085-2.956)$ & 0.032 \\
\hline Length of surgical incision (cm) & $7.352(4.235-12.761)$ & $<0.001$ & NA & \\
\hline Duration of operation (h) & $8.906(5.078-15.621)$ & $<0.001$ & $4.571(1.787-11.692)$ & 0.002 \\
\hline$P_{1} \%$ & $16.369(8.826-30.356)$ & $<0.001$ & $3.400(1.302-8.878)$ & 0.012 \\
\hline $\mathrm{P}_{2} \%$ & $0.667(0.402-1.109)$ & 0.119 & NA & \\
\hline Level & $0.817(0.498-1.450)$ & 0.952 & NA & \\
\hline Levels of fusion (\%) & $1.639(1.114-2.412)$ & 0.012 & NA & \\
\hline Intraoperative infusion of crystalloids (ml) & $0.569(0.341-0.949)$ & 0.031 & NA & \\
\hline Intraoperative infusion of colloids (ml) & $0.765(0.469-1.248)$ & 0.283 & NA & \\
\hline Autologous blood transfusion (\%) & $1.019(0.601-1.730)$ & 0.943 & NA & \\
\hline Allogeneic blood transfusion (\%) & $1.771(1.012-3.097)$ & 0.045 & NA & \\
\hline Preoperative total cholesterol (mmol/L) & $9.384(5.287-16.655)$ & $<0.001$ & $7.161(2.523-20.322)$ & $<0.001$ \\
\hline Preoperative triglyceride $(\mathrm{mmol} / \mathrm{L})$ & $5.196(3.059-8.828)$ & $<0.001$ & NA & \\
\hline Preoperative Hct (\%) & $1.576(0.965-2.576)$ & 0.069 & NA & \\
\hline Preoperative Hb (g/L) & $0.713(0.436-1.167)$ & 0.178 & NA & \\
\hline Preoperative ALB (g/L) & 4.478 (2.519-7.959) & $<0.001$ & NA & \\
\hline Preoperative PT (s) & $13.872(7.632-25.214)$ & 0.089 & NA & \\
\hline Preoperative APTT (s) & $0.700(0.424-1.156)$ & 0.164 & NA & \\
\hline Preoperative Fib (mg/dL) & $0.525(0.317-0.868)$ & 0.012 & $0.378(0.179-0.598)$ & 0.029 \\
\hline
\end{tabular}

Abbreviations: BMI body mass index, COPD chronic obstructive pulmonary disease, JOA Japanese Orthopaedic Association, VAS visual analogue score, SF-36 36-Item Short Form Health Survey, $P_{1} \%$ percentages of vertebral height restoration, $P_{2} \%$ percentages of vertebral height loss, $H c t$ hematocrit, $H b$ hemoglobin, $A L B$ albumin, $P T$ prothrombin time, APTT activated partial thromboplastin time, OR odds ratio, $C l$ confidence interval, $N A$ not available

the best of our knowledge, there is very little literature that explores this association. Based on previous literature, we suggest that non-esterified fatty acids may have played an important role in oxidative stress $[27,28]$. Unsaturated fatty acids stimulate reactive oxygen species (ROS) activation in neutrophils [29]. Subsequently, activated ROS attacks erythrocyte membrane proteins via nicotinamide adenine dinucleotide oxidase, causing membrane perforations and thus disruption of the plasma membrane and having an indirect hemolytic effect [29].

An important concern in the treatment of thoracolumbar burst fracture is timing [30-32]. Generally, the timing of the operation depends on the severity of the nerve injury. At present, there is a preliminary consensus on the timing of surgery for incomplete nerve injury. Compared with complete nerve injury, patients with incomplete nerve injury can benefit more from early 


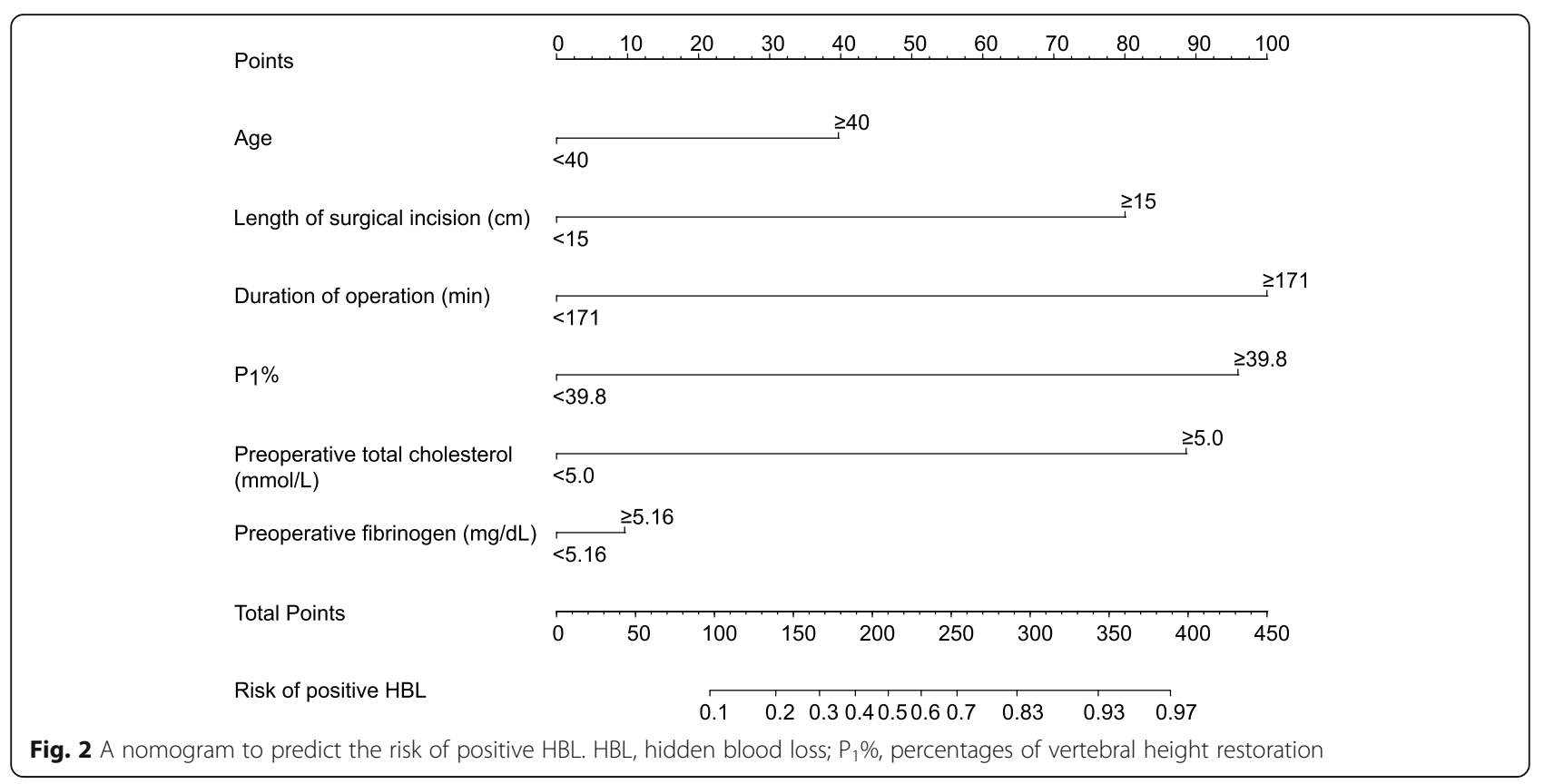

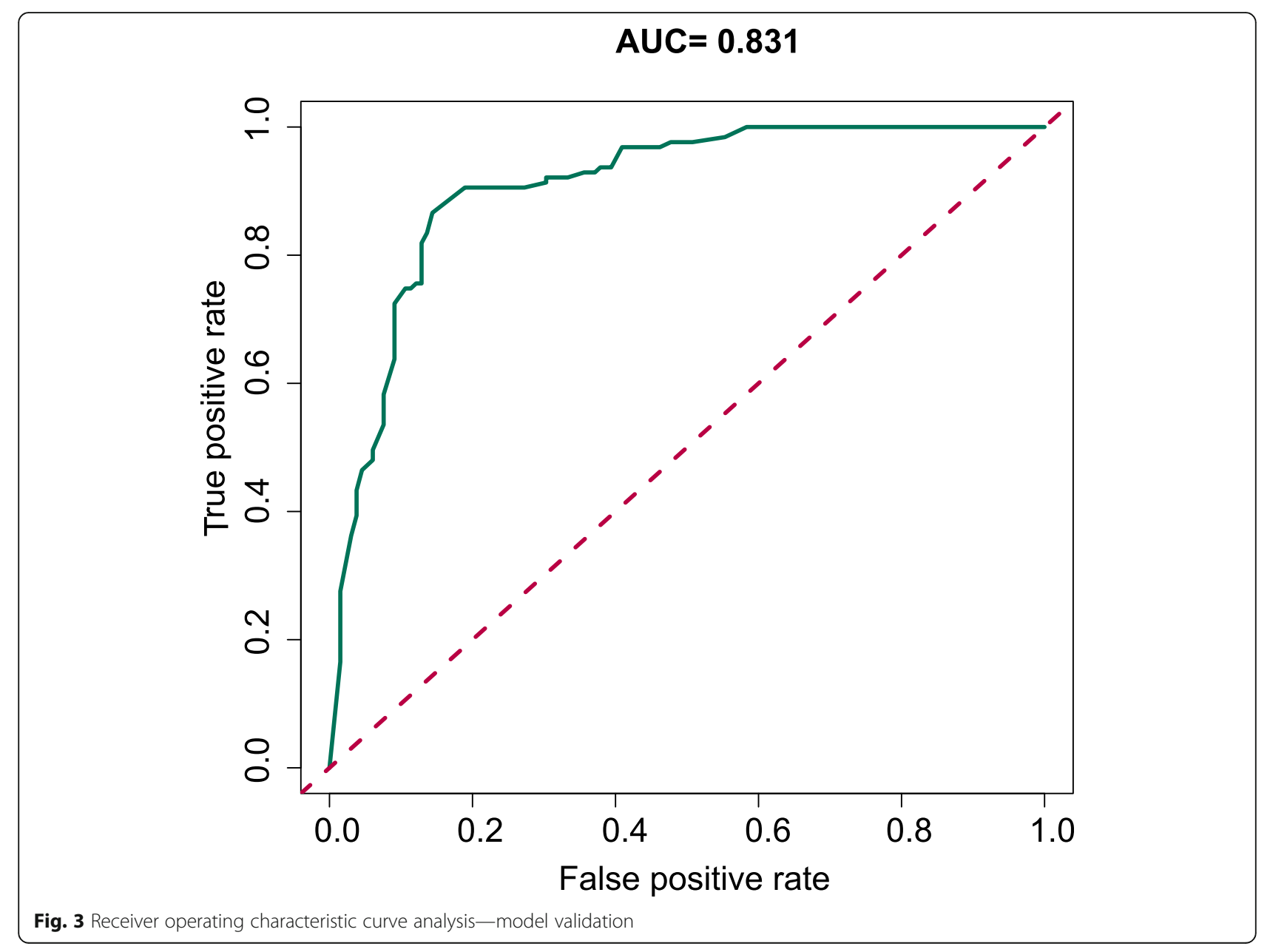




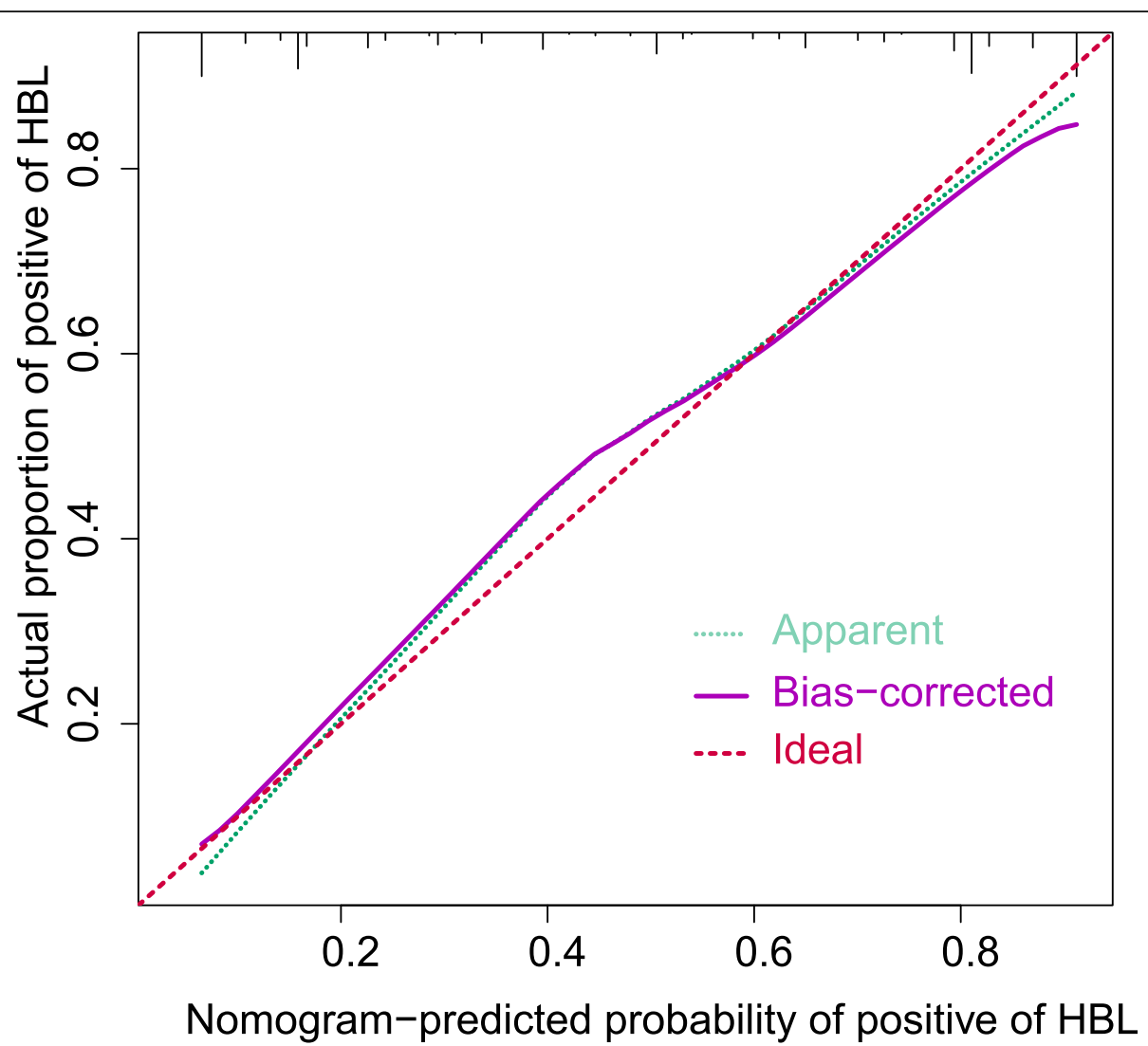

Fig. 4 Calibration curves of the nomogram. The lines in the figure represent the apparent value, the bias corrected value, and ideal value. The apparent and the bias corrected values are close to each other, which means the nomogram has a good predictive performance

emergency decompression [22, 32]. However, the definition of an early surgical time window demands serious consideration.

Most previous studies believed that the early surgical time window was $24-72 \mathrm{~h}$ after injury, but some scholars also believed that the early operation time should be within 12-24h after injury [30, 32]. Based on published literature and our experience, we defined the early time window as within $48 \mathrm{~h}$ after injury. Multivariate logistic regression analysis identified surgical time window < $48 \mathrm{~h}$ as an independent risk factor for positive HBL. In a previous retrospective study, patients were divided into 3 groups according to the timing of surgery for patients with thoracolumbar burst fractures. The timing of patients undergoing surgery in different groups was categorized as $12-24 \mathrm{~h}$ post-injury, 3-5 days post injury, and 7-10 days post-injury. One interesting finding was that the proportion of HBL to TBL in these 3 groups was $52.43 \%, 45.10 \%$, and $49.41 \%$, respectively. Traumatic stress may have played an important role in it. Traumatic stress via stimulation of tumor necrosis factor- $\alpha$ (TNF- $\alpha$ ), interleukins (IL), and other cytokines are synthesized to inhibit erythroid formation. At the same time, bone fractures lead to disruption of the local microcirculation and local tissue hypoxia, thereby causing activation of the anaerobic glycolytic pathway and an increase in lactate concentration [33]. These all stay, causing telangiectasia, leakage of tissue fluid, and inducing a fall in effective circulating blood volume. When patients undergo emergency surgery, it is often difficult to correct the homeostasis resulting from trauma in a timely manner. Therefore, we would have resulted in an enlarged HBL when calculated using the Gross formula.

Interestingly, our results demonstrated that $\mathrm{P}_{1} \%$ was identified as a risk factor for HBL, which could presumably be ascribed to blood infiltration into the tissue compartments. Namely, the higher $\mathrm{P}_{1} \%$, the more penetrable tissue compartments could be formed. It means that the more the vertebral height is restored, the bigger the "cavity" will be [7]. Meanwhile, with increased vertebral height restoration, there will be a larger fracture gap around the vertebral walls, which may lead to more infiltration of blood into the tissue compartments. Another noteworthy finding in our study was that fibrinogen was identified as a risk factor for HBL. Fibrinogen is an inflammatory protein that gets converted to fibrin in the 


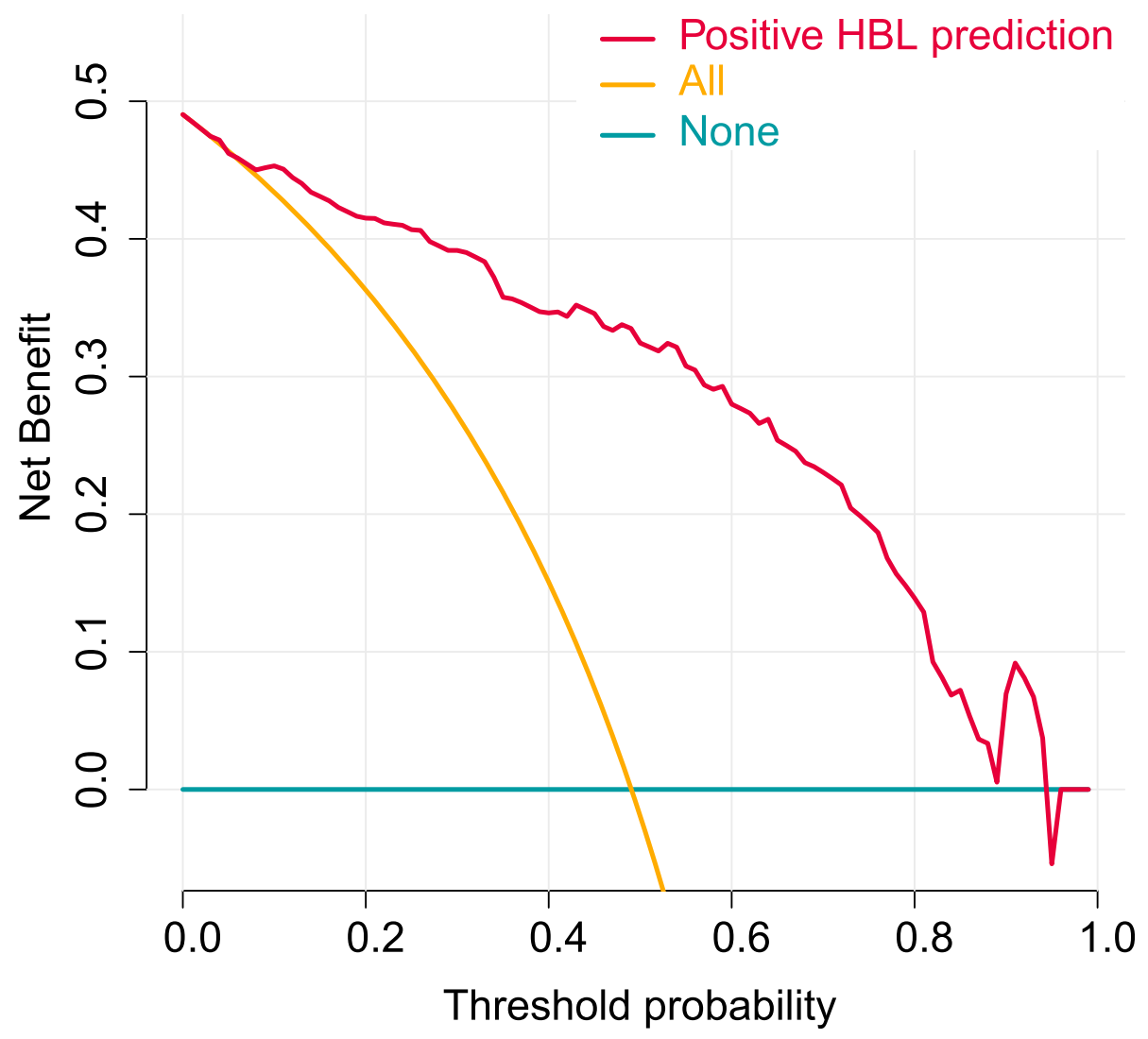

Fig. 5 Decision curve analysis for nomogram prediction of risk of positive HBL in the perioperative period of single-level thoracolumbar burst fracture. The $y$-axis shows the net benefit: $x$-axis shows the threshold probability. The blackish green line represents the net benefit of our nomogram. The yellow line indicates the hypothesis that all patients had positive HBL. The blue line represents the hypothesis that no patients had positive HBL

presence of thrombin and directly influences platelet adhesion and activation. It was previously shown that levels were negatively correlated with HBL, which was similar to our findings $[8,34]$.

Here, we developed a novel predictive nomogram for predicting the risk of positive HBL in single-level TBF patients during the perioperative period. Our nomogram can demonstrate the key parameters graphically and can individually evaluate the incidence of risk of positive HBL. We believe it can contribute to clinical decisionmaking and doctor-patient communication. More importantly, we can identify patients with a high risk of positive for HBL. Additionally, the nomogram may provide opportunities that might lead to improvements in perioperative management.

There were a few limitations to our study that should not be ignored. First, due to the retrospective and observational nature of the study, the results are subject to limitations. Second, there was a lack of external validation for our proposed model, especially in other regions and countries. Third, specific data could not be obtained from the medical records or was missing. Finally, only patients with single-level TBF were enrolled. Patients with multi-level TBF need to be further studied in the future. Therefore, in future studies, our team should collaborate with the remaining medical centers and provide more data for more in-depth evaluation and validation of prediction models.

\section{Conclusions}

In summary, by using a single center data in our hospital, we investigated the risk factors for HBL. Consequently, we established an individualized nomogram prediction model for positive HBL. Our nomogram is with satisfied performance in the evaluation of the risk of positive HBL, which may help clinical decision making. However, external validation will be needed in the future.

\section{Abbreviations}

HBL: Hidden blood loss; TBF: Thoracolumbar burst fracture; AUC: Area under the receiver operating characteristic curves; DCA: Decision curve analysis; PLDF: Posterior lumbar decompression and fusion; MIS-TLIF: Minimally invasive transforaminal interbody fusion; PLIF: Posterior lumbar internal fixation; CSF: Cerebrospinal fluid leakage; BMI: Body mass index;

COPD: Chronic obstructive pulmonary disease; JOA: Japanese Orthopaedic 
Association; VAS: Visual analogue score; SF-36: 36-Item Short Form Health Survey; $P_{1} \%$ : Percentages of vertebral height restoration; $P_{2} \%$ : Percentages of vertebral height loss; Hct: Hematocrit; Hb: Hemoglobin; ALB: Albumin; PT: Prothrombin time; APTT: Activated partial thromboplastin time; TLIC S: Thoracolumbar Injury Classification and Severity Score; ROS: Reactive oxygen species; TNF-a: Tumor necrosis factor-a; IL: Interleukins

\section{Supplementary Information}

The online version contains supplementary material available at https://doi. org/10.1186/s13018-021-02699-6.

Additional file 1: Figure S1. The receiver operating characteristic (ROC) analysis was used to determine the optimal cut-off values for continuous variables.

\section{Acknowledgements \\ Not applicable.}

\section{Authors' contributions}

HSW collected the data, analyzed the data, and drafted the manuscript. QL supervised the project and reviewed the manuscript. ZRT, WLL, and TTF conceived of the study, participated in its design and coordination, and helped to draft the manuscript. QL was responsible for the whole project, designed the study, and supervised the study. All authors read and approved the final manuscript.

\section{Funding}

No funds were received in support of this work.

\section{Availability of data and materials}

The data set supporting the conclusion of this article is available on request to the corresponding author

\section{Declarations}

\section{Ethics approval and consent to participate}

The study was approved by an institutional ethics committee at the Baoj City Hospital of Traditional Chinese Medicine (Ethics application number: 2021GYKJD5N). Considering that this work was a retrospective study, the ethics committee waived the requirement for informed consent from patients.

\section{Consent for publication}

Not applicable.

\section{Competing interests}

The authors declare that they have no competing interests.

\section{Author details}

'Department of Orthopedics, Baoji City Hospital of Traditional Chinese Medicine, 43 Baofu Road, Baoji 721000, Shaanxi Province, People's Republic of China. ${ }^{2}$ Department of Endocrinology, Baoji City Hospital of Traditional Chinese Medicine, Baoji, Shaanxi Province, People's Republic of China. ${ }^{3}$ Department of Computer Science, City University of Hong Kong, Hong Kong, People's Republic of China. ${ }^{4}$ Department of Orthopedics, Xianyang Central Hospital, Xianyang, People's Republic of China. ${ }^{5}$ Clinical Medical Research Center, Xianyang Central Hospital, Xianyang, People's Republic of China.

\section{Received: 1 August 2021 Accepted: 30 August 2021}

\section{Published online: 15 September 2021}

\section{References}

1. Holdsworth F. Fractures, dislocations, and fracture-dislocations of the spine. J Bone Joint Surg Br Vol. 1963;45(1):6-20. https://doi.org/10.1302/0301-62 0X.45B1.6.

2. Vollmer DG, Gegg C. Classification and acute management of thoracolumbar fractures. Neurosurg Clin North Am. 1997:8(4):499-507. https://doi.org/10.1016/S1042-3680(18)30296-1.
3. Aebi M. Classification of thoracolumbar fractures and dislocations. Eur Spine J. 2010;19(1):2-7. https://doi.org/10.1007/s00586-009-1114-6.

4. Patel AA, Dailey A, Brodke DS, Daubs M, Harrop J, Whang PG, et al. Thoracolumbar spine trauma classification: the Thoracolumbar Injury Classification and Severity Score system and case examples. J Neurosurg Spine. 2009;10(3):201-6. https://doi.org/10.3171/2008.12.SPINE08388.

5. Denis $F$. The three column spine and its significance in the classification of acute thoracolumbar spinal injuries. Spine. 1983;8(8):817-31.

6. Rajasekaran S, Vaccaro AR, Kanna RM, Schroeder GD, Oner FC, Vialle L, et al. The value of CT and MRI in the classification and surgical decision-making among spine surgeons in thoracolumbar spinal injuries. Eur Spine J. 2017; 26(5):1463-9. https://doi.org/10.1007/s00586-016-4623-0.

7. Chen ZX, Sun ZM, Jiang C, Zhang H, Tong MJ, Lin Y, et al. Comparison of hidden blood loss between three different surgical approaches for treatment of thoracolumbar fracture. J Invest Surg. 2019;32(8):755-60. https://doi.org/10.1080/08941939.2018.1458925.

8. Yin M, Chen G, Yang J, Tong Z, Xu J, Huang Q, et al. Hidden blood loss during perioperative period and the influential factors after surgery of thoracolumbar burst fracture: a retrospective case series. Medicine (Baltimore). 2019;98(13):e14983. https://doi.org/10.1097/MD.0000000000014 983.

9. Sehat K, Evans R, Newman J. How much blood is really lost in total knee arthroplasty?: correct blood loss management should take hidden loss into account. Knee. 2000;7(3):151-5. https://doi.org/10.1016/S0968-0160(00)0004 7-8.

10. Wen L, Jin D, Xie W, Li Y, Chen W, Ding J, Xu J, Ren D. Hidden Blood Loss in Posterior Lumbar Fusion Surgery: An Analysis of Risk Factors. Clin Spine Surg. 2018;31(4):180-4.

11. Smorgick Y, Baker KC, Bachison CC, Herkowitz HN, Montgomery DM, Fischgrund JS. Hidden blood loss during posterior spine fusion surgery. Spine J. 2013;13(8):877-81. https://doi.org/10.1016/j.spinee.2013.02.008.

12. Xu D, Chen X, Li Z, Ren Z, Zhuang Q, Li S. Tranexamic acid reduce hidden blood loss in posterior lumbar interbody fusion (PLIF) surgery. Medicine (Baltimore). 2020;99(11):e19552. https://doi.org/10.1097/MD.000000000001 9552

13. Zhang $R$, Xing F, Yang Z, Lin G, Chu J. Analysis of risk factors for perioperative hidden blood loss in patients undergoing transforaminal lumbar interbody fusion. J Int Med Res. 2020;48(8):300060520937848. https://doi.org/10.1177/0300060520937848.

14. Yuksel MO, Gurbuz MS, Is M, Somay H. Is the thoracolumbar injury classification and severity score (TLICS) superior to the AO thoracolumbar injury classification system for guiding the surgical management of unstable thoracolumbar burst fractures without neurological deficit? Turk Neurosurg. 2018;28(1):94-8. https://doi.org/10.5137/1019-5149.JTN.19094-16.2.

15. Dawkins RL, Miller JH, Ramadan OI, Lysek MC, Kuhn EN, Rocque BG, et al. Thoracolumbar injury classification and severity score in children: a reliability study. J Neurosurg Pediatr. 2018;21(3):284-91. https://doi.org/10.3171/2017. 7.PEDS1720

16. Kim BD, Smith TR, Lim S, Cybulski GR, Kim JY. Predictors of unplanned readmission in patients undergoing lumbar decompression: multiinstitutional analysis of 7016 patients. J Neurosurg Spine. 2014;20(6):606-16. https://doi.org/10.3171/2014.3.SPINE13699.

17. Nadler SB, Hidalgo JU, Bloch T. Prediction of blood volume in normal human adults. Surgery. 1962;51(2):224-32.

18. Danks NP, Sharma PN, Sarstedt M. Model selection uncertainty and multimodel inference in partial least squares structural equation modeling (PLS-SEM)[J]. J Bus Res. 2020;113.

19. Lenth R, Lenth MR. Package 'Ismeans'. Am Statistician. 2018;34(4):216-21.

20. Chalmers RP, Adkins MC. Writing effective and reliable Monte Carlo simulations with the SimDesign package. Quantitat Methods Psychol. 2020; 16(4):248-80. https://doi.org/10.20982/tqmp.16.4.p248.

21. Sehat K, Evans R, Newman J. Hidden blood loss following hip and knee arthroplasty: correct management of blood loss should take hidden loss into account. J Bone Joint Surg Br Vol. 2004;86(4):561-5. https://doi.org/1 0.1302/0301-620X.86B4.14508.

22. da Silva OT, Rodrigues SA, Ghizoni E, Tedeschi H, Joaquim AF. Can injury type/subtype of the new Aospine subaxial cervical trauma classification dictate patient's treatment? Int J Orthop. 2020;7(6):1397-401. https://doi. org/10.17554/j.issn.2311-5106.2020.07.396.

23. Yang E-Z, Xu J-G, Liu X-K, Jin G-Y, Xiao W, Zeng B-F, et al. An RCT study comparing the clinical and radiological outcomes with the use of PLIF or 
TLIF after instrumented reduction in adult isthmic spondylolisthesis. Eur Spine J. 2016;25(5):1587-94. https://doi.org/10.1007/s00586-015-4341-z.

24. Vas V, Senger K, Dörr K, Niebel A, Geiger H. Aging of the microenvironment influences clonality in hematopoiesis; 2012.

25. Ju Z, Jiang H, Jaworski M, Rathinam C, Gompf A, Klein C, et al. Telomere dysfunction induces environmental alterations limiting hematopoietic stem cell function and engraftment. Nat Med. 2007;13(6):742-7. https://doi.org/1 $0.1038 / \mathrm{nm} 1578$.

26. Chang W-T, Chen J-S, Hung Y-K, Tsai W-C, Juang J-N, Liu P-Y.

Characterization of aging-associated cardiac diastolic dysfunction. PLoS One. 2014;9(5):e97455. https://doi.org/10.1371/journal.pone.0097455.

27. Yuan T, Cong Y, Meng J, Qian H, Ye W, Sun W-S, et al. Arachidonic acid causes hidden blood loss-like red blood cell damage through oxidative stress reactions. J Surg Res. 2017;211:14-20. https://doi.org/10.1016/j.jss.201 6.11 .060 .

28. Yuan T, Fan W-B, Cong Y, Xu H-D, Li C-J, Meng J, et al. Linoleic acid induces red blood cells and hemoglobin damage via oxidative mechanism. Int J Clin Exp Pathol. 2015;8(5):5044-52.

29. Guerra BA, Otton R. Impact of the carotenoid astaxanthin on phagocytic capacity and ROS/RNS production of human neutrophils treated with free fatty acids and high glucose. Int Immunopharmacol. 2011;11(12):2220-6. https://doi.org/10.1016/j.intimp.2011.10.004.

30. Mushlin H, Kole MJ, Chryssikos T, Cannarsa G, Schwartzbauer G, Aarabi B. AOSpine subaxial cervical spine injury classification system: The relationship between injury morphology, admission injury severity, and long-term neurologic outcome. World Neurosurg. 2019;130:e368-74. https://doi.org/1 0.1016/j.wneu.2019.06.092.

31. Aarabi B, Oner C, Vaccaro AR, Schroeder GD, Akhtar-Danesh N. Application of AOSpine subaxial cervical spine injury classification in simple and complex cases. J Orthop Trauma. 2017;31(4):S24-32. https://doi.org/10.1097/ BOT.0000000000000944

32. Du J-P, Fan Y, Zhang J-N, Liu J-J, Meng Y-B, Hao D-J. Early versus delayed decompression for traumatic cervical spinal cord injury: application of the AOSpine subaxial cervical spinal injury classification system to guide surgical timing. Eur Spine J. 2019;28(8):1855-63. https://doi.org/10.1007/s00586-01905959-6.

33. Ito Z, Shibayama M, Nakamura S, Yamada M, Kawai M, Takeuchi M, et al. Clinical comparison of unilateral biportal endoscopic laminectomy versus microendoscopic laminectomy for single-level laminectomy: a single-center, retrospective analysis. World Neurosurg. 2021;148:e581-8. https://doi.org/1 0.1016/j.wneu.2021.01.031.

34. Xu S, Liang Y, Wang J, Yu G, Guo C, Zhu Z, et al. Blood loss of posterior lumbar interbody fusion on lumbar stenosis in patients with rheumatoid arthritis: a case-control study. Spine (Phila Pa 1976). 2019;44(17):E1045-52. https://doi.org/10.1097/BRS.0000000000003037.

\section{Publisher's Note}

Springer Nature remains neutral with regard to jurisdictional claims in published maps and institutional affiliations.

Ready to submit your research? Choose BMC and benefit from:

- fast, convenient online submission

- thorough peer review by experienced researchers in your field

- rapid publication on acceptance

- support for research data, including large and complex data types

- gold Open Access which fosters wider collaboration and increased citations

- maximum visibility for your research: over $100 \mathrm{M}$ website views per year

At BMC, research is always in progress.

Learn more biomedcentral.com/submissions 